\title{
Extracorporeal carbon dioxide removal for acute hypercapnic respiratory failure
}

\author{
Luis Morales-Quinteros ${ }^{1 *} \mathbb{0}$, Lorenzo Del Sorbo ${ }^{2}$ and Antonio Artigas ${ }^{1,3,4}$
}

\begin{abstract}
In the past, the only treatment of acute exacerbations of obstructive diseases with hypercapnic respiratory failure refractory to medical treatment was invasive mechanical ventilation (IMV). Considerable technical improvements transformed extracorporeal techniques for carbon dioxide removal in an attractive option to avoid worsening respiratory failure and respiratory acidosis, and to potentially prevent or shorten the duration of IMV in patients with exacerbation of COPD and asthma. In this review, we will present a summary of the pathophysiological rationale and evidence of $\mathrm{ECCO}_{2} \mathrm{R}$ in patients with severe exacerbations of these pathologies.
\end{abstract}

Keywords: $\mathrm{COPD}, \mathrm{Asthma}, \mathrm{ECCO}_{2} \mathrm{R}$, Invasive mechanical ventilation, Noninvasive mechanical ventilation

\section{Background}

Patients with obstructive lung diseases, such as asthma and chronic obstructive pulmonary disease (COPD), may experience acute exacerbations with severe hypercapnic respiratory failure. Hypercapnia results from acute worsening of expiratory flow limitation caused by the increased small airway resistance with consequent development of dynamic alveolar hyperinflation and intrinsic positive end-expiratory pressure (PEEP). In the most severe cases, these may be refractory to conventional therapies and mechanical ventilation, becoming life-threatening.

Extracorporeal carbon dioxide removal $\left(\mathrm{ECCO}_{2} \mathrm{R}\right)$ represents an attractive approach in this setting.

The last decade has seen an increasing interest in the provision of extracorporeal support for respiratory failure, as demonstrated by the progressively increasing number of scientific publications on this topic. In particular, remarkable interest has been focused on extracorporeal carbon dioxide removal $\left(\mathrm{ECCO}_{2} \mathrm{R}\right)$, due to the relative ease and efficiency in blood $\mathrm{CO}_{2}$ clearance granted by extracorporeal gas exchangers as compared to oxygen delivery [1].

\footnotetext{
*Correspondence: luchomq2077@gmail.com

1 Intensive Care Unit, Hospital Universitario Sagrado Corazón, Barcelona, Spain

Full list of author information is available at the end of the article
}

In recent years, a new generation of $\mathrm{ECCO}_{2} \mathrm{R}$ devices has been developed. More efficient veno-venous (VV)$\mathrm{ECCO}_{2} \mathrm{R}$ devices have become available and have replaced the arterio-venous approach, having the advantage of not requiring arterial puncture.

The new VV-ECCO ${ }_{2} \mathrm{R}$ devices offer lower resistance to blood flow, have smaller priming volumes, and provide a much more efficient gas exchange with relatively low extracorporeal blood flows $(0.4-1 \mathrm{~L} / \mathrm{min})$ [2]. The technology of these devices is now comparable to that of renal dialysis and has been experimented in several animal and human studies, demonstrating significant reduction in arterial $\mathrm{CO}_{2}$ and improvement in the work of breathing [3-6].

\section{Pathophysiological rationale for $\mathrm{ECCO}_{2} \mathrm{R}$ in obstructive lung diseases}

In both asthma and COPD exacerbations, diffuse narrowing of the airways results in detrimental physiological consequences. Airway narrowing prevents the lungs from completely emptying ("air trapping") due to resistance to expiratory flow and bronchial closure at higher than normal lung volumes. Air trapping results in dynamic hyperinflation (DHI) [7] which is the excessive increase in end-expiratory lung volume above the relaxation volume of the respiratory system, generating intrinsic positive end-expiratory pressure (auto-PEEP) [8]. As a result, the patient breathes at higher total lung volumes, 
due to increased residual volume [9], which may reduce tidal ventilation. The net effect is that the work of breathing increases significantly. The diaphragm, intercostal muscles, and even the abdominal muscles are overloaded causing respiratory muscle fatigue and dyspnea [10].

Pharmacotherapy with bronchodilators and systemic corticosteroids are part of the medical therapies, administered specifically to reduce the pathophysiological airflow obstruction and improve symptoms.

The recognition for the need for noninvasive ventilation (NIV) is indicated if the patient fails to improve clinically and if the level of $\mathrm{pH}$ remains less than 7.32 despite medical therapy [11]. However, NIV fails in up to $20-30 \%$ of patients and IMV is indicated with specific ventilation strategies, targeting relative short inspiratory time and longer expiratory time $[12,13]$.

Overall, the goal of mechanical ventilation is to provide adequate gas exchange and reduce the work of breathing while waiting for airflow obstruction to resolve. However, mechanical ventilation itself may aggravate alveolar hyperinflation by worsening DHI, which may lead to worsened hypercapnia, barotrauma, alveolar rupture leading to pneumothorax and further hemodynamic deterioration [14].

Furthermore, if treated with IMV, these patients receive sedatives and likely neuromuscular blockade to facilitate ventilatory support [15]. Sedation and paralysis preclude mobilization, promoting neuromuscular deconditioning, and potentially contributing to the long-term cognitive sequelae of critical illness [16].

When conventional therapeutic options are not successful, novel therapies such as extracorporeal life support are entertained as a possible salvage therapeutic modality.

During exacerbation, relieving the native lung from at least part of the $\mathrm{CO}_{2}$ elimination with $\mathrm{ECCO}_{2} \mathrm{R}$ could potentially improve the acid-base balance, reduce patient's work of breathing with a consequent reduction in respiratory rate and ventilatory drive, and lower alveolar ventilation. The lower tidal volumes and respiratory rate result in the extension of the expiratory time, suiting better the high expiratory time constant of the respiratory system with expiratory flow limitation. By these physiological mechanisms, $\mathrm{ECCO}_{2} \mathrm{R}$ can counteract the vicious circle of dynamic hyperinflation, and its detrimental respiratory and cardiovascular consequences. The derived beneficial effects on respiratory mechanics, ventilatory muscle efficiency, work of breathing, and cardiovascular function may improve gas exchanges and relieve dyspnea. By these mechanisms, $\mathrm{ECCO}_{2} \mathrm{R}$ thus can potentially prevent NIV failure, facilitate weaning from IMV, and therefore contribute to avoid the unwanted complications of sedation and immobilization.

\section{$\mathrm{ECCO}_{2} \mathrm{R}$ technical aspects and principle}

$E C C O_{2} R$ is designed to remove carbon dioxide $\left(\mathrm{CO}_{2}\right)$ and, unlike extracorporeal membrane oxygen (ECMO), does not provide significant oxygenation.

The device consists of a drainage cannula placed in a large central vein or artery, a membrane lung (artificial gas exchanger), and a return cannula into the venous system (Fig. 1). Blood is pumped through the membrane lung, and $\mathrm{CO}_{2}$ is removed by diffusion. A flowing gas known as "sweep gas" containing little or no $\mathrm{CO}_{2}$ runs along the other side of the membrane, ensuring a diffusion gradient from blood to the other side, hence promoting $\mathrm{CO}_{2}$ removal.

In contrast to ECMO, where the need for oxygenation requires high blood flow rates, $\mathrm{ECCO}_{2} \mathrm{R}$ requires much lower blood flow rates, due to the significant differences in $\mathrm{CO}_{2}$ and oxygen $\left(\mathrm{O}_{2}\right)$ kinetics. Almost all the $\mathrm{O}_{2}$ in blood is carried by hemoglobin, which displays sigmoidal saturation kinetics. Assuming normal hemoglobin and venous $\mathrm{O}_{2}$ content, each liter of venous blood can only carry an extra $40-60 \mathrm{~mL}$ of $\mathrm{O}_{2}$ before the hemoglobin is fully saturated. Blood flows of $5-7 \mathrm{~L} / \mathrm{min}$ through the extracorporeal artificial membrane lung are therefore required to supply enough $\mathrm{O}_{2}$ for an average adult. Conversely, most $\mathrm{CO}_{2}$ in blood is dissolved or in the form of bicarbonate, displaying linear kinetics without saturation. Considering that $1 \mathrm{~L}$ of blood is transported around $500 \mathrm{~mL}$ of $\mathrm{CO}_{2}$, in a perfectly efficient system flow of 0.5 $\mathrm{L} / \mathrm{min}$ would be enough to remove all of the $\mathrm{CO}_{2}$ produced by an average adult, which is about $250 \mathrm{~mL} / \mathrm{min}[2$, $17,18]$. Also, $\mathrm{CO}_{2}$ diffuses more readily than $\mathrm{O}_{2}$ across extracorporeal membranes because of higher solubility. However, in practice, $\mathrm{ECCO}_{2} \mathrm{R}$ is usually able to remove up to $25 \%$ of carbon dioxide production given the limitations of blood flow and membrane efficiency [19]. As the rate of $\mathrm{CO}_{2}$ clearance greatly depends on the fresh sweep gas flow through the membrane lung, this is usually maximized in the low blood flow $\mathrm{ECCO}_{2} \mathrm{R}$ systems. Therefore, the efficiency of $\mathrm{CO}_{2}$ clearance of the different available devices is critically determined by other important parameters, including the size of the cannula, the rate of recirculation of blood in the circuit, the efficiency of the pump, the total surface area of the artificial lung, and the cardiac preload $[20,21]$. Importantly, given the low blood flow through the extracorporeal circuit and the even lower flow achieved when the blood is crossing the large surface area of the artificial gas exchanger, the risk of thrombosis plays also a key role in $\mathrm{CO}_{2}$ clearance.

\section{VV-ECCO 2}

In the veno-venous configuration, blood is drawn from a central vein by a draining cannula, using a centrifugal or roller pump to generate flow across the membrane. $\mathrm{CO}_{2}$ 


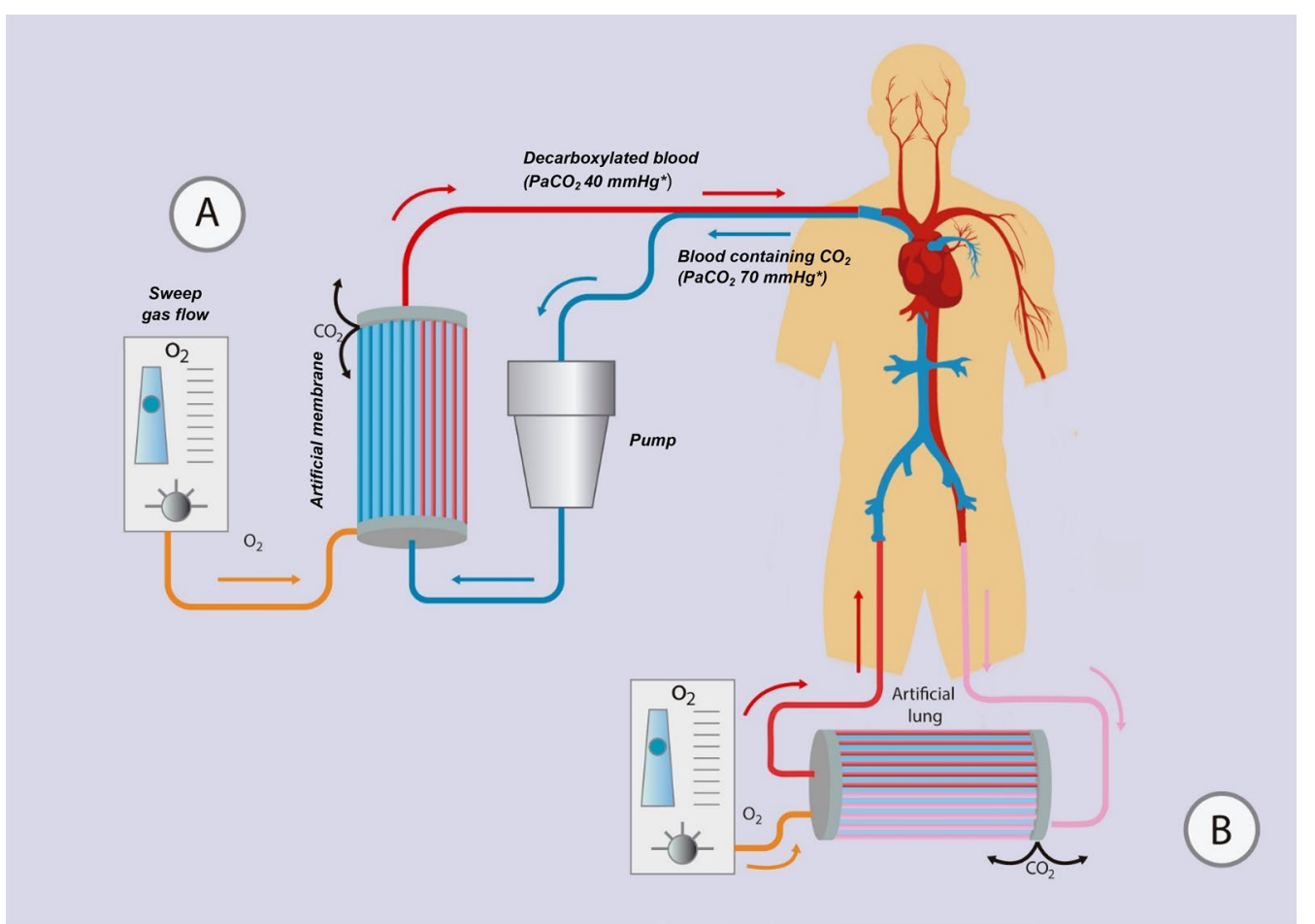

Fig. $1 \mathrm{ECCO}_{2} \mathrm{R}$ common configurations. a Minimally invasive veno-venous $\mathrm{ECCO}_{2} \mathrm{R}$ system with a single venous vascular access through a double-lumen cannula that can be inserted in the internal jugular or femoral vein. $\mathbf{b}$ Pumpless arterio-venous $\mathrm{ECCO}_{2} \mathrm{R}$ system with the placement of the membrane in the circuit connecting the femoral artery with the contralateral vein. ${ }^{*} \mathrm{PaCO}_{2}$ values are purely indicative

is removed by the effect of the "sweep gas," and blood is then returned into the venous circulation (Fig. 1a). Single site cannulation is possible using a double-lumen cannula. This approach allows $\mathrm{ECCO}_{2} \mathrm{R}$ through the use of smaller cannulas (15-19F), commonly introduced via the right internal jugular vein. The setup is very similar to renal replacement therapy, and in fact, some systems are trying to combine the two in one [22, 23] (NCT02590575). One of the advantages of VV-ECCO ${ }_{2} \mathrm{R}$ compared to the $\mathrm{AV}$ approach is the less invasiveness by avoiding arterial cannulation, and the potential for early mobilization of patients. It is also possible to set up an $\mathrm{ECCO}_{2} \mathrm{R}$ system through cannulation of two central veins, one for drainage and the other for reinfusion (e.g., femoral-femoral configuration).

\section{$\mathrm{AV}-\mathrm{ECCO}_{2} \mathrm{R}$}

In the $\mathrm{AV}-\mathrm{ECCO}_{2} \mathrm{R}$ configuration, the blood flows from the femoral artery, usually instrumented with percutaneous cannulation, to the contralateral femoral vein, creating a pumpless arterio-venous (AV) bypass, equipped with an artificial gas exchanger across the AV shunt, which allows the "sweep gas" to remove $\mathrm{CO}_{2}$ (Fig. 1b). This pumpless systems require an arterio-venous pressure gradient $\geq 60 \mathrm{mmHg}$ and a cardiac index $>3 \mathrm{~L} / \mathrm{min} /$ $\mathrm{m}^{2}$, which is unsuitable for hemodynamically unstable patients $[18,24]$. Furthermore, cannulation of a major artery can result in distal ischemia [25], although measuring the artery diameter with ultrasound and selecting a cannula that occupies less than $70 \%$ of the lumen reduces this risk [26].

\section{Indications and evidence}

\section{Chronic obstructive pulmonary disease}

Chronic obstructive pulmonary disease (COPD) is a significant worldwide health burden. Currently, it is the fourth leading cause of death worldwide, and is the only leading cause of death that is rising, and will likely become the third cause of death by 2020 [27, 28].

Acute exacerbations of COPD (aeCOPD) constitute a significant cause of morbidity and mortality among these patients. Patients with moderate to severe acute exacerbations develop alveolar hyperinflation that may lead to increased work of breathing, muscle fatigue, and hypercapnia, creating a vicious loop refractory to medical treatment [29-31]. The standard respiratory support in this setting is NIV, which however, fails in up to $30 \%$ of patients with aeCOPD, prompting intubation and IMV [32-34]. In recent meta-analysis and observational studies, it has been reported that the in-hospital mortality 
of patients with aeCOPD requiring IMV is as high as 25-39\% [35-38].

Patients with COPD requiring IMV develop a considerable reduction in respiratory muscle strength, with higher risk of prolonged weaning and/or failure to wean, compared to other causes of acute hypercapnic respiratory failure. Up to $60 \%$ of the ventilatory time in these patients is spent for weaning [39] and is very likely to require a tracheotomy. The prolonged time on IMV results in an increased potential risk of ventilator-induced lung injury, ventilator-associated pneumonia, and ventilator-induced diaphragmatic dysfunction, in addition to the abovementioned complications associated with prolonged sedation and immobilization.

\section{Evidence and clinical trials of $\mathrm{ECCO}_{2} \mathrm{R}$ in aeCOPD to date}

One of the first reports on the application of $\mathrm{ECCO}_{2} \mathrm{R}$ to support respiratory function of a COPD patient was published in Pesenti et al. [40]. However, the technique was abandoned due to technical complications.

As the medical community regained interest in $\mathrm{ECCO}_{2} \mathrm{R}$, investigators began applying the technique to prevent intubation or to assist weaning from IMV in this patients' population. Several studies in both VV and AV configurations were published, including a meta-analysis (Table 1).

\section{$\mathrm{ECCO}_{2} \mathrm{R}$ to avoid IMV}

Brederlau et al. [41] described their experience in three patients that failed NIV for severe aeCOPD. They applied a pumpless AV $\mathrm{ECCO}_{2} \mathrm{R}$ device with the goal of avoiding endotracheal intubation. The $\mathrm{ECCO}_{2} \mathrm{R}$ flow ranged between 1.1 and $1.6 \mathrm{~L} / \mathrm{min}$, with the sweep gas flow varying from 3 to $10 \mathrm{~L} / \mathrm{min}$. Shortly after beginning $\mathrm{ECCO}_{2} \mathrm{R}$, the $\mathrm{PaCO}_{2}$ fell significantly, and also the respiratory rate dropped from 38,45 , and 37 breaths/min to 15,25 , and 18 breaths/min, respectively.

Kluge et al. [5] in the same year evaluated the safety and efficacy of using an AV pumpless extracorporeal lung assist in 21 COPD patients who did not respond to NIV and compared them to 21 matched controls treated with IMV. The use of AV ECCO ${ }_{2} \mathrm{R}$ resulted in the decrease of $\mathrm{PaCO}_{2}$ after $24 \mathrm{~h}$ and obviated the need for IMV in $90 \%$ of the experimental arm. Although the experimental group had a shorter hospital length of stay, there was no significant difference in mortality at 28 days $(19 \%$ with $\mathrm{ECCO}_{2} \mathrm{R}$ vs. $24 \%$ without $\mathrm{ECCO}_{2} \mathrm{R}$ ) or 6 months (both groups $33 \%$ ) compared to the control group.

Burki et al. [42] treated 20 hypercapnic COPD patients with VV $\mathrm{ECCO}_{2} \mathrm{R}$ through a 15.5-Fr dual-lumen cannula achieving a mean blood flow of $430 \mathrm{~mL} / \mathrm{min}$. Of the 20 patients, seven were at risk of failing NIV, two were difficult to wean from NIV, and 11 had failed liberation from MV. With $\mathrm{ECCO}_{2} \mathrm{R}$, none of the patients failing NIV required endotracheal intubation, and both patients with difficult weaning from NIV were weaned. However, only three of the 11 IMV patients were liberated successfully. Moreover, significant complications arose in a number of patients: bleeding requiring blood transfusion was reported in three patients, deep vein thrombosis was diagnosed in one patient after removal of the $\mathrm{ECCO}_{2} \mathrm{R}$ catheter, one patient experienced pneumothorax due to catheter insertion, and one died from hemorrhage when the iliac vein was perforated during $\mathrm{ECCO}_{2} \mathrm{R}$ catheter placement.

Del Sorbo et al. [4] compared 25 patients with aeCOPD treated with NIV + VV ECCO ${ }_{2} \mathrm{R}$ versus 21 historical controls treated with NIV alone with regard to the cumulative incidence of intubation. They reported that $\mathrm{ECCO}_{2} \mathrm{R}$ with a 14-Fr dual-lumen catheter and blood flow rates of $177-333 \mathrm{~mL} / \mathrm{min}$ not only improved respiratory acidosis but also reduced the need for intubation by $75 \%$ (12\% vs. $33 \% ; p=0.047)$ and significantly reduced the in-hospital mortality ( $8 \%$ vs. $35 \% ; p=0.035$ ). However, this came with a cost of $52 \%$ prevalence of $\mathrm{ECCO}_{2} \mathrm{R}$-related side effects and led the authors to suggest the end point of future studies should be long-term mortality.

Braune et al. [43] in the ECLAIR study showed that IMV was avoided in $56 \%$ of cases treated with VV $\mathrm{ECCO}_{2} \mathrm{R}$, which was associated with a high incidence of complications. However, in this study, there was an inclusion of patients with relative contraindications to NIV, and there was an unexpectedly high incidence of hypoxemic patients [44].

Finally, Morelli et al. [45] confirmed the efficacy of VV $\mathrm{ECCO}_{2} \mathrm{R}$ (with a flow rate of $250-450 \mathrm{~mL} / \mathrm{min}$ through a 13-Fr dual-lumen cannula) in reducing the $\mathrm{PaCO}_{2}$ in a series of 30 patients with acute hypercapnic respiratory failure due to aeCOPD, who refused endotracheal intubation after failing NIV. The duration of $\mathrm{ECCO}_{2} \mathrm{R}$ was 2-16 days, and it was possible to prevent endotracheal intubation in 27 patients.

\section{$\mathrm{ECCO}_{2} \mathrm{R}$ to facilitate weaning from IMV}

Cardenas et al. [46] made the first attempt to use modern ECLS components for VV ECCO $\mathrm{E}_{2} \mathrm{R}$ in a patient with aeCOPD. They demonstrated a successful reduction in $\mathrm{PaCO}_{2}$, minute ventilation, and ventilator pressures.

Burki et al. [42] in a subgroup of 11 patients receiving $\mathrm{IMV}, \mathrm{ECCO}_{2} \mathrm{R}$ allowed the weaning from mechanical ventilator in only three patients.

Abrams et al. [3] reported five older patients (age $73 \pm 8.7$ years) with aeCOPD who failed NIV, requiring IMV. After an average of $16.5 \pm 5.9 \mathrm{~h}$ of IMV, $\mathrm{ECCO}_{2} \mathrm{R}$ was initiated. By using a dual-lumen cannula (20-23 Fr) with blood flow rates of 1-1.7 Lt/min, with a sweep 


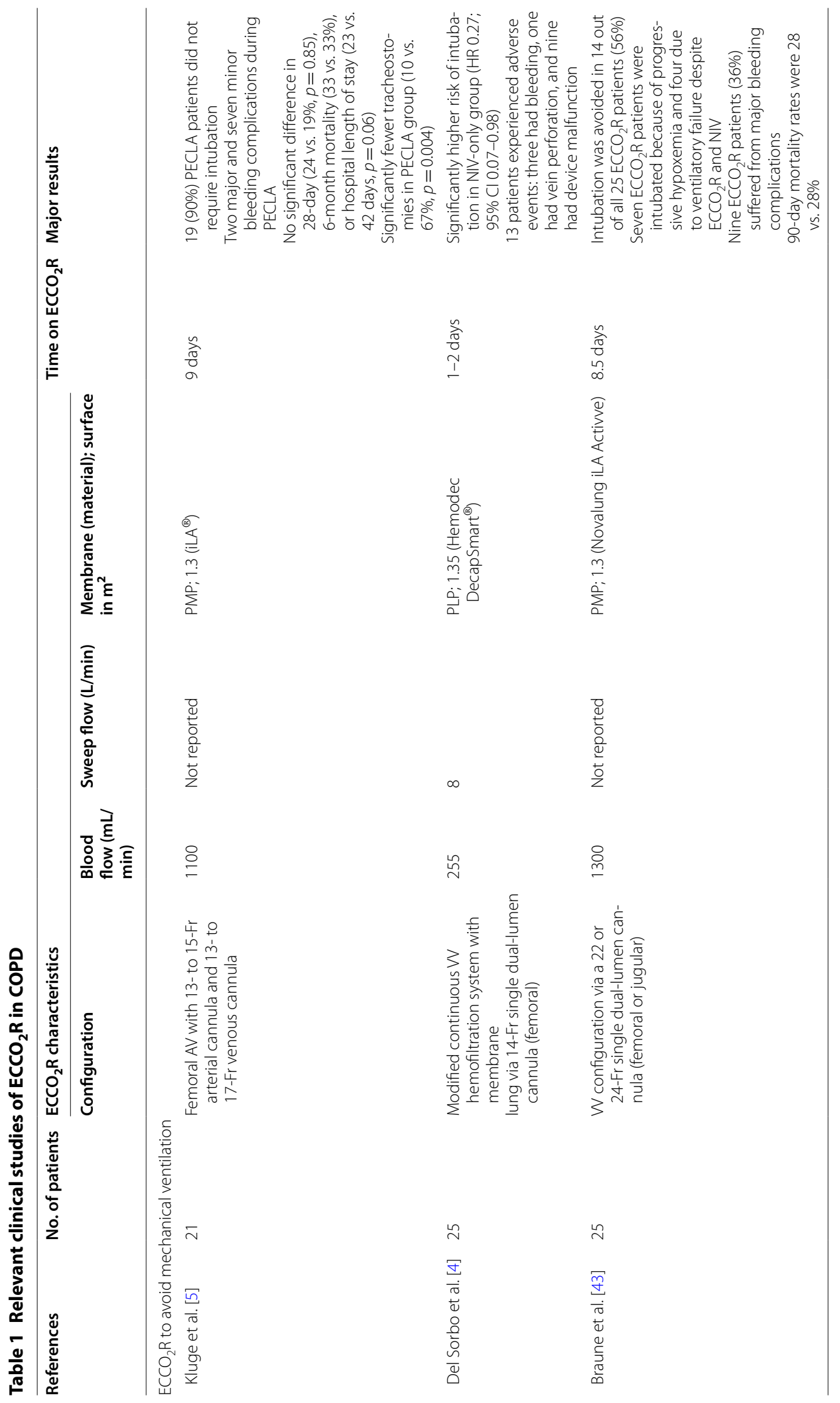




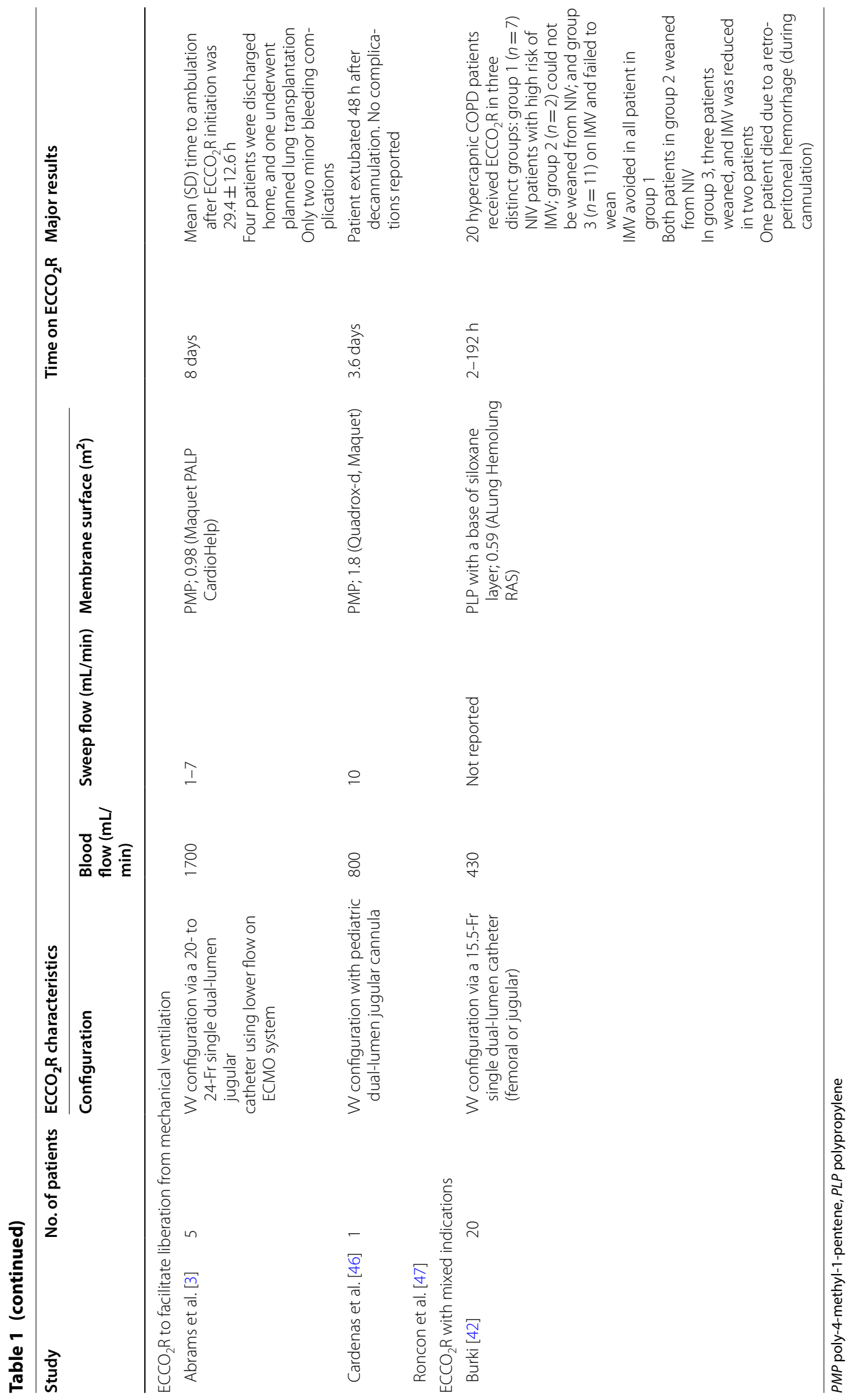


gas flow from 1 to $7 \mathrm{~L} / \mathrm{min}$, they were able to extubate all five patients within $24 \mathrm{~h}$ of treatment (median duration of $\mathrm{MV}$ post $\mathrm{ECCO}_{2} \mathrm{R}=4 \mathrm{~h}$, range 1.5-21.5 h). Once extubated, patients were rehabilitated while on $\mathrm{ECCO}_{2} \mathrm{R}$, with a mean time to ambulation of $29.4 \pm 12.6 \mathrm{~h}$ after $\mathrm{ECCO}_{2} \mathrm{R}$. Moreover, all patients survived to hospital discharge.

Roncon-Albuquerque Jr. et al. [47] using a pediatric VV ECMO system (with blood flow rates of $0.9 \mathrm{~L} / \mathrm{min}$ through a $19 \mathrm{Fr}$ dual-lumen cannula placed in the right jugular vein) in two patients with aeCOPD reported early extubation after $72 \mathrm{~h}$ and patient mobilization out of bed at day 6.

\section{Future studies on $\mathrm{ECCO}_{2} \mathrm{R}$ for COPD}

More data will be forthcoming on the application of $\mathrm{ECCO}_{2} \mathrm{R}$ in the management of patients with COPD exacerbations from a number of ongoing or planned clinical trials (Table 2).

Despite the strong physiological rationale, the existing data are not sufficient to support the routine use of $\mathrm{ECCO}_{2} \mathrm{R}$ in patients with aeCOPD, as randomized controlled trials investigating the efficacy of $\mathrm{ECCO}_{2} \mathrm{R}$ in improving important patient centered outcome are lacking, and the intervention is associated with a high rate of complications.

Furthermore, the relevant incidence of $\mathrm{ECCO}_{2} \mathrm{R}$-related complications considerably affects the choice of the target patient population of randomized controlled trials, and hence their inclusions and exclusion criteria. The application of $\mathrm{ECCO}_{2} \mathrm{R}$ to prevent IMV in aeCOPD patients at high risk of NIV failure has a remarkable potential clinical impact, but exposes a number of patients, who will not require IMV, to the unnecessary risk of $\mathrm{ECCO}_{2} \mathrm{R}$-related complications. The application of $\mathrm{ECCO}_{2} \mathrm{R}$ in aeCOPD patients intubated after NIV failure to accelerate liberation from IMV exposed patients simultaneously to the complications of two invasive treatments. In both scenarios, given the high mortality rate associated with IMV in this obviously vulnerable patient population, these studies should be powered to demonstrate a mortality benefit.

The development of new $\mathrm{ECCO}_{2} \mathrm{R}$ technology with less associated complications will allow the study of $\mathrm{ECCO}_{2} \mathrm{R}$ also in patients with milder severity of aeCOPD or even in stable COPD patients to prevent the occurrence of exacerbations.

\section{Severe acute asthma}

Asthma is an inflammatory disorder of the airways characterized by airway hyperactivity with bronchospasm, mucosal swelling, and mucus production. The standard treatment of severe acute asthma consists of measures to reverse airflow obstruction. $\beta 2$ agonists and steroids are the mainstays of treatment [12]. Other available adjunct therapies including anticholinergics, magnesium sulfate, methylxanthines, ketamine, and heliox have been utilized with varying results [48].

Despite advances in asthma therapy, asthma mortality has remained stable in recent years. One reason is the occurrence of status asthmaticus, which can be unresponsive to initial treatment and may lead to hypercapnic respiratory failure despite maximal therapy, and in the most severe cases requires IMV.

Approximately, $4 \%$ of all patients hospitalized for acute asthma require IMV, which is associated with increased in-hospital mortality compared with patients who do not require mechanical ventilation (7 vs. $0.2 \%$ ) [49].

Although necessary, mechanical ventilation may aggravate alveolar hyperinflation as it was described above. To prevent these potential detrimental effects, $\mathrm{ECCO}_{2} \mathrm{R}$ has been applied as rescue therapy.

$\mathrm{ECCO}_{2} \mathrm{R}$ as an adjunct to IMV for refractory asthma was first reported in 1981 [50]. Subsequently, several case series have been reported (Table 3) [51-55]. In the international Extracorporeal Life Support Organization (ELSO) registry, the use of ECMO for asthma has been reported in 24 adult patients between 1986 and 2006. Hypercapnia, rather than hypoxemia, was the main gas exchange derangement treated with ECMO, suggesting that a less invasive approach, such as low flow $\mathrm{ECCO}_{2} \mathrm{R}$, could also be suitable in these cases. Indeed, the use of $\mathrm{ECCO}_{2} \mathrm{R}$ in patients with asthmatic exacerbation has been reported, although in a limited number of cases.

\section{Complications}

Although $\mathrm{ECCO}_{2} \mathrm{R}$ seems to be effective in improving or mitigating hypercapnic acidosis and possibly in reducing the rate of endotracheal intubation, its use is associated with a range of vascular, hematological, and other complications (Table 4).

Arterial cannulation is associated with higher risk than venous catheterization, with specific complications including distal limb ischemia, compartment syndrome of the lower limb requiring fasciotomy or limb amputation, as devastating consequences [18].

The occurrence of bleeding events is the most frequent complication of $\mathrm{ECCO}_{2} \mathrm{R}$. The low flow renders systemic anticoagulation mandatory, increasing the risk of significant bleeding including cerebral, gastrointestinal, and nasopharyngeal bleeds. In the studies on $\mathrm{ECCO}_{2} \mathrm{R}$ for COPD to date, the rate of clinically significant hemorrhagic complications ranges between $2 \%$ and $50 \%$ [56].

Thrombocytopenia is also commonly observed, as well as hemolysis. 


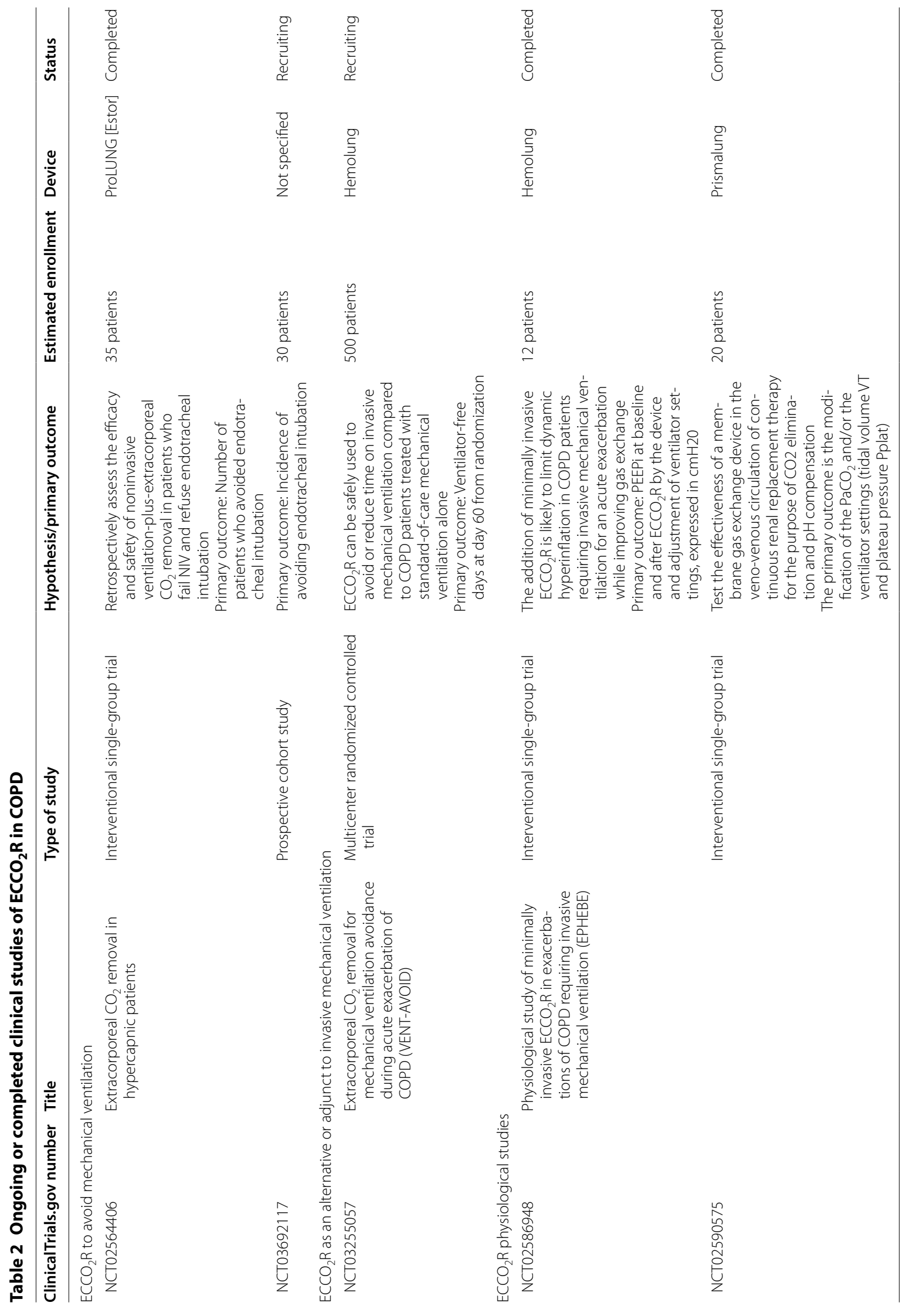




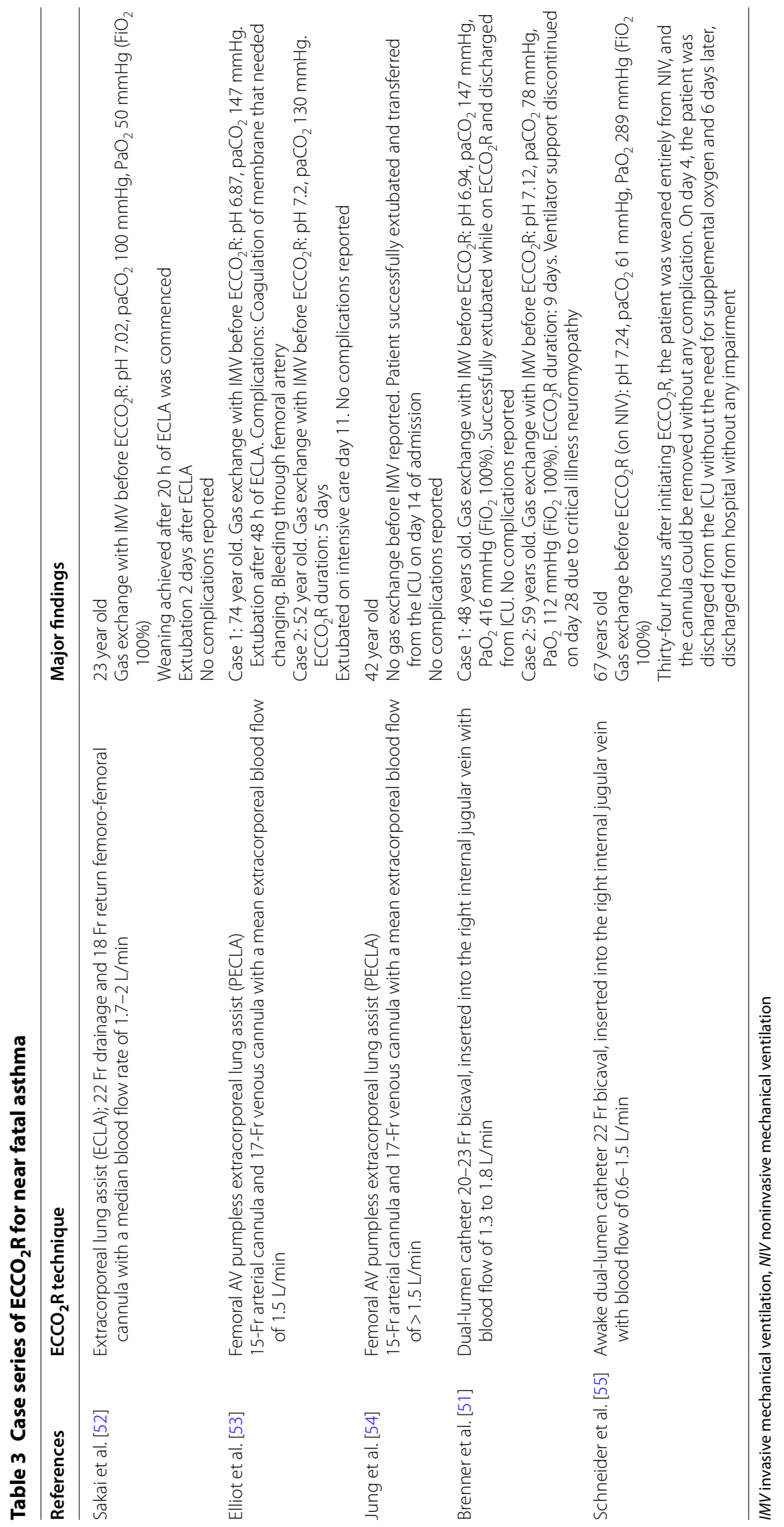


Table $4 \mathrm{ECCO}_{2} \mathrm{R}$-related complications

\begin{tabular}{ll}
\hline Patient-related complications & Anticoagulation-related bleeding \\
& Hemolysis \\
& Heparin-induced thrombocytopenia \\
& Acquired coagulopathy \\
& Recirculation \\
Catheter-related complications & Catheter-site bleeding \\
& Catheter malposition, dislodgement \\
& or kinking \\
& Catheter infection \\
& Vascular occlusion \\
& Thrombosis \\
& Hematoma, aneurism, pseudoaneu- \\
rysm formation \\
Pump failure \\
Oxygenator failure \\
Heat-exchanger malfunction \\
Clot formation \\
Air embolism \\
\end{tabular}

Conversely, thrombus formation is higher at lower blood flow rates because of increased exposure time to the membrane lung and circuit. Clots may detach and enter the patient's bloodstream, plugging the membrane or obstructing the cannula if anticoagulation is not achieved.

\section{Conclusion}

In the past, $\mathrm{ECCO}_{2} \mathrm{R}$ was a complex technique requiring intensive monitoring and surgical expertise. Due to a high rate of complications, it was avoided by all but few high expertise centers. With newer simplified systems, $\mathrm{ECCO}_{2} \mathrm{R}$ devices can be easily used and can be initiated by most intensivists. However, given the lack of conclusive clinical evidence and the relatively high rate of associated complications, its use should be restricted to investigational applications in specific cohorts of patients.

In summary, minimally invasive $\mathrm{ECCO}_{2} \mathrm{R}$ appears very promising for patients with acute exacerbation of obstructive diseases refractory to conventional treatment, but systematic evaluation is needed to prove its clinical efficacy.

\begin{abstract}
Abbreviations
AV-ECCO 2 R: arterio-venous extracorporeal carbon dioxide removal; COPD: chronic obstructive pulmonary disease; $\mathrm{CO}_{2}$ : carbon dioxide; $\mathrm{DHI}$ : dynamic hyperinflation; $\mathrm{ECCO}_{2} \mathrm{R}$ : extracorporeal carbon dioxide removal; ECMO: extracorporeal membrane oxygenation; IMV: invasive mechanical ventilation; NIV: noninvasive ventilation; PECLA: pumpless extracorporeal lung assist; PEEP: positive end-expiratory pressure; PLP: polypropylene; PMP: poly-4-methyl1-pentene; $\mathrm{VV}$-ECCO${ }_{2} \mathrm{R}$ : veno-venous extracorporeal carbon dioxide removal.
\end{abstract}

\section{Acknowledgements}

We want to acknowledge Eduardo Radicy for creating the figure for this manuscript.

\section{Authors' contributions}

All the authors have contributed equally for the elaboration of this article. All authors read and approved the final manuscript.

\section{Funding}

This article did not receive sponsorship for publication.

\section{Availability of data and materials}

Data sharing not applicable to this article as no datasets were generated or analyzed during the current study.

\section{Ethics approval and consent to participate}

Not applicable.

\section{Consent for publication}

Not applicable.

\section{Competing interests}

The authors declare that they have no competing interests.

\section{Author details}

${ }^{1}$ Intensive Care Unit, Hospital Universitario Sagrado Corazón, Barcelona, Spain. ${ }^{2}$ Interdepartmental Division of Critical Care Medicine, Toronto General Hospital, University of Toronto, Toronto, Canada. ${ }^{3}$ Critical Care Center, ParcTaulí Hospital Universitari, Institut d'Investigació i Innovació Parc Taulí I3PT, Universitat Autònoma de Barcelona, Sabadell, Spain. ${ }^{4}$ CIBER Enfermedades Respiratorias, Instituto de Salud Carlos III, Madrid, Spain.

Received: 18 February 2019 Accepted: 24 June 2019

Published online: 02 July 2019

\section{References}

1. Boyle AJ, Sklar MC, MCNamee JJ, et al. Extracorporeal carbon dioxide removal for lowering the risk of mechanical ventilation: research questions and clinical potential for the future. Lancet Respir Med. 2018;6:874-84

2. MacLaren G, Combes A, Bartlett RH. Contemporary extracorporeal membrane oxygenation for adult respiratory failure: life support in the new era. Intensive Care Med. 2012;38:210-20.

3. Abrams DC, Brenner K, Burkart KM, et al. Pilot study of extracorporeal carbon dioxide removal to facilitate extubation and ambulation in exacerbations of chronic obstructive pulmonary disease. Ann Am Thorac Soc. 2013;10:307-14.

4. Del Sorbo L, Pisani L, Filippini C, et al. Extracorporeal $\mathrm{CO}_{2}$ removal in hypercapnic patients at risk of noninvasive ventilation failure: a matched cohort study with historical control. Crit Care Med. 2015;43:120-7.

5. Kluge S, Braune SA, Engel M, et al. Avoiding invasive mechanical ventilation by extracorporeal carbon dioxide removal in patients failing noninvasive ventilation. Intensive Care Med. 2012;38:1632-9.

6. Diehl JL, Piquilloud L, Richard JC, et al. Effects of extracorporeal carbon dioxide removal on work of breathing in patients with chronic obstructive pulmonary disease. Intensive Care Med. 2016;42(5):951-2.

7. Pellegrino R, Violante B, Nava S, et al. Expiratory airflow limitation and hyperinflation during methacholine-induced bronchoconstriction. J Appl Physiol. 1993:75:1720-7.

8. Laghi F, Goyal A. Auto-PEEP in respiratory failure. Miner Anestesiol. 2012;78:201-21.

9. Wagers SS, Jaffe EFIC. Development structure and physiology in normal and asthmatic lung. In: Adkinson Jr NY, Yunginger JW, Busse WW, et al., editors. Middleton's allergy principles practice. Mosby St Louis: Elsevier; 2003.

10. Ranieri VM, Grasso S, Mascia L, et al. Effects of proportional assist ventilation on inspiratory muscle effort in patients with chronic obstructive pulmonary disease and acute respiratory failure. Anesthesiology. 1997;86:79-91.

11. Plant PK, Owen JL, Elliott MW. Early use of non-invasive ventilation for acute exacerbations of chronic obstructive pulmonary disease on general respiratory wards: a multicentre randomised controlled trial. Lancet. 2000;355:1931-5 
12. National Heart, Lung and Blood Institute NAE and PP. Expert Panel Report 3: guidelines for the diagnosis and management of asthma: full report 2007. 2017. http://nhlbi.nih.gov/guidelines/asthma/asthgdln.pdf.

13. Sethi JM, Siegel MD. Mechanical ventilation in chronic obstructive lung disease. Clin Chest Med. 2000;21:799-818.

14. Blanch L, Bernabé F, Lucangello U. Measurement of air trapping, intrinsic positive end-expiratory pressure, and dynamic hyperinflation in mechanically ventilated patients. Respir Care. 2005;50:110-23.

15. Marhong JD, Telesnicki T, Munshi L, et al. Mechanical ventilation during extracorporeal membrane oxygenation. Ann Am Thorac Soc. 2014;11:956-61.

16. Langer T, Santini A, Bottino N, et al. "Awake" extracorporeal membrane oxygenation (ECMO): pathophysiology, technical considerations, and clinical pioneering. Crit Care. 2016;20:150.

17. Gattinoni L, Pesenti A, Kolobow T, et al. A new look at therapy of the adult respiratory distress syndrome: motionless lungs. Int Anesth Clin. 1983;21:97-117.

18. Cove ME, MacLaren G, Federspiel WJ, et al. Bench to bedside review: extracorporeal carbon dioxide removal, past present and future. Crit Care. 2012:16(5):232.

19. Terragni P, Maiolo G, Ranieri VM. Role and potentials of low-flow $\mathrm{CO}_{2}$ removal system in mechanical ventilation. Curr Opin Crit Care. 2012;18:93-8.

20. Schmidt M, Tachon G, Devilliers C, et al. Blood oxygenation and decarboxylation determinants during venovenous ECMO for respiratory failure in adults. Intensive Care Med. 2013;39(5):838-46.

21. Del Sorbo L, Cypel M, Fan E. Extracorporeal life support for adults with severe acute respiratory failure. Lancet Respir Med. 2013;2:154-64.

22. Winiszewski $\mathrm{H}$, Aptel F, Belon F, et al. Daily use of extracorporeal $\mathrm{CO}_{2}$ removal in a critical care unit: indications and results. J Intensive Care. 2018:6:36.

23. May AG, Sen A, Cove ME, et al. Extracorporeal $\mathrm{CO}_{2}$ removal by hemodialysis: in vitro model and feasibility. Intensive Care Med Exp. 2017:5:20.

24. Flörchinger B, Philipp A, Klose A, et al. Pumpless extracorporeal lung assist: a 10-year institutional experience. Ann Thorac Surg. 2008;86:410-7.

25. Bein T, Weber F, Philipp A, et al. A new pumpless extracorporeal interventional lung assist in critical hypoxemia/hypercapnia. Crit Care Med. 2006:34:1372-7

26. Zimmermann M, Bein T, Arlt M, et al. Pumpless extracorporeal interventional lung assist in patients with acute respiratory distress syndrome: a prospective pilot study. Crit Care. 2009;13:R10.

27. Calverley PM, Walker P. Chronic obstructive pulmonary disease. Lancet. 2003;362:1053-61.

28. Chapman KR, Mannino DM, Soriano JB, et al. Epidemiology and costs of chronic obstructive pulmonary disease. Eur Respir J. 2006;27:188-207.

29. Barberà JA, Roca J, Ferrer A, et al. Mechanisms of worsening gas exchange during acute exacerbations of chronic obstructive pulmonary disease. Eur Respir J. 1997;10:1285-91.

30. Roberts CM, Stone RA, Buckingham RJ, et al. Acidosis, non-invasive ventilation and mortality in hospitalised COPD exacerbations. Thorax. 2011;66:43-8

31. Oliven A, Kelsen SG, Deal EC, et al. Mechanisms underlying $\mathrm{CO}_{2}$ retention during flow-resistive loading in patients with chronic obstructive pulmonary disease. J Clin Invest. 1983;71:1442-9.

32. Phua J, Kong $\mathrm{K}$, Lee $\mathrm{KH}$, et al. Noninvasive ventilation in hypercapnic acute respiratory failure due to chronic obstructive pulmonary disease vs. other conditions: effectiveness and predictors of failure. Intensive Care Med. 2005;31:533-9.

33. Confalonieri M, Garuti G, Cattaruzza MS, et al. A chart of failure risk for noninvasive ventilation in patients with COPD exacerbation. Eur Respir J. 2005;25:348-55

34. Quinnell TG, Pilsworth S, Shneerson JM, et al. Prolonged invasive ventilation following acute ventilatory failure in COPD: weaning results, survival, and the role of noninvasive ventilation. Chest. 2006:129:133-9.

35. Chandra D, Stamm JA, Taylor B, et al. Outcomes of noninvasive ventilation for acute exacerbations of chronic obstructive pulmonary disease in the United States, 1998-2008. Am J Respir Crit Care Med. 2012;185:152-9.

36. Tabak YP, Sun X, Johannes RS, et al. Mortality and need for mechanical ventilation in acute exacerbations of chronic obstructive pulmonary disease: development and validation of a simple risk score. Arch Intern Med. 2009;169:1595-602.

37. Patil SP, Krishnan JA, Lechtzin NDG. In-hospital mortality following acute exacerbations of chronic obstructive pulmonary disease. Arch Intern Med. 2003:163:1180-6.

38. Demoule A, Girou E, Richard JC, et al. Benefits and risks of success or failure of noninvasive ventilation. Intensive Care Med. 2006;32:1756-65.

39. Nava S, Ambrosino N, Clini E, et al. Noninvasive mechanical ventilation in the weaning of patients with respiratory failure due to chronic obstructive pulmonary disease. A randomized, controlled trial. Ann Intern Med. 1998;128:721-8.

40. Pesenti A, Rossi GP, Pelosi P, et al. Percutaneous extracorporeal $\mathrm{CO}_{2}$ removal in a patient with bullous emphysema with recurrent bilateral pneumothoraces and respiratory failure. Anesthesiology. 1990;72:307-14.

41. Brederlau J, Wurmb T, Wilczek S, et al. Extracorporeal lung assist might avoid invasive ventilation in exacerbation of COPD. Eur Respir J. 2012;40:783-5.

42. Burki NK, Mani RK, Herth FJF, et al. COPD a novel extracorporeal $\mathrm{CO}_{2}$ removal results of a pilot study of hypercapnic respiratory failure in patients with COPD. Chest. 2013;143(3):678-86.

43. Braune $S$, Sieweke A, Brettner F, et al. The feasibility and safety of extracorporeal carbon dioxide removal to avoid intubation in patients with COPD unresponsive to noninvasive ventilation for acute hypercapnic respiratory failure (ECLAIR study): multicentre case-control study. Intensive Care Med. 2016:42:1437-44

44. Del Sorbo L, Fan E, Nava S, et al. ECCO2R in COPD exacerbation only for the right patients and with the right strategy. Intensive Care Med. 2016;42:1830-1.

45. Morelli A, D'Egidio A, Orecchioni A, et al. Extracorporeal $\mathrm{CO}_{2}$ removal in hypercapnic patients who fail noninvasive ventilation and refuse endotracheal intubation: a case series. Intensive Care Med Exp. 2015;3(Suppl 1):A824

46. Cardenas VJ Jr, Lynch JE, Ates R, et al. Venovenous carbon dioxide removal in chronic obstructive pulmonary disease: experience in one patient. ASAIO J. 2009;55:420-2

47. Roncon-Albuquerque R Jr, Carona G, Neves A, et al. Venovenous extracorporeal CO2 removal for early extubation in COPD exacerbations requiring invasive mechanical ventilation. Intensive Care Med. 2014;40:1969-70.

48. Wong JJ, Lee JH, Turner DA, et al. A review of the use of adjunctive therapies in severe acute asthma exacerbation in critically ill children. Expert Rev Respir Med. 2014;8:423-41.

49. Krishnan V, Diettte GN, Rand CS, et al. Mortality in patients hospitalized for asthma exacerbations in the United States. Am J Respir Crit Care Med. 2006;174:633-55

50. MacDonnell KF, Moon HS, Sekar TS, et al. Extracorporeal membrane oxygenator support in a case of severe status asthmaticus. Ann Thorac Surg. 1981;31:171-5.

51. Brenner K, Abrams DC, Agerstrand CL, et al. Extracorporeal carbon dioxide removal for refractory status asthmaticus: experience in distinct exacerbation phenotypes. Perfusion. 2014;29:26-8

52. Sakai M, Ohteki $H$, Kazuyosi D, et al. Clinical use of extracorporeal lung assist for a patient in status asthmaticus. Ann Thorac Surg. 1996;62:885-7.

53. Elliot SC, Paramasivam K, Oram J, et al. Pumpless extracorporeal carbon dioxide removal for life-threatening asthma. Crit Care Med. 2007:35:945-8.

54. Jung $C$, Lauten $A$, Pfeifer $R$, et al. Pumpless extracorporeal lung assist for the treatment of severe refractory status asthmaticus. J Asthma. 2011:48:111-3.

55. Schneider TM, Bence T, Brettner F. "Awake" ECCO2R superseded intubation in a near-fatal asthma attack. J Intensive Care. 2017:5:53.

56. Sklar MC, Beloncle F, Katsios CM, et al. Extracorporeal carbon dioxide removal in patients with chronic obstructive pulmonary disease: a systematic review. Intensive Care Med. 2015;41:1752-62.

\section{Publisher's Note}

Springer Nature remains neutral with regard to jurisdictional claims in published maps and institutional affiliations. 